\title{
Technological Capability in Metal Fabricating Firms in Southwestern Nigeria
}

\author{
Victor Oluwasina Sobanke ${ }^{1}$, Matthew Olugbega Ilori ${ }^{2}$, Stephen Akinade Adegbite ${ }^{3}$ \\ ${ }^{1}$ National Centre for Technology Management, Obafemi Awolowo University, Ile-Ife, Nigeria; ${ }^{2}$ African Institute for Science Policy \\ and Innovation, Obafemi Awolowo University, Ile-Ife, Nigeria; ${ }^{3}$ Centre for Industrial Research and Development, Obafemi Awo- \\ lowo University, Ile-Ife, Nigeria. \\ Email: v_sobanke@hotmail.com
}

Received March 28 ${ }^{\text {th }}, 2012$; revised April 29 $9^{\text {th }}, 2012$; accepted May 22 ${ }^{\text {nd }}, 2012$

\begin{abstract}
The study assessed the technological capability in the metal fabricating firms in southwestern Nigeria. A technology capability index (TCI) was used in assessing 200 randomly sampled firms. Data for the study was analyzed by using descriptive analysis. The results showed a variation in the TCI scores of firms with micro, small and medium fabricating firms scoring an average of 0.82, 1.10 and 1.54 respectively. Firms which reported that process innovation were incremental are $24.8 \%$; new to the firm $(100.0 \%)$ and creative (3.0\%). Similarly, product innovation variables showed that $85.5 \%$ were incremental; imitation (95.5\%) and creativity (50.4\%). The study suggests the need for policy intervenetion to enhance the knowledge and skills of the operators.
\end{abstract}

Keywords: Technological Capability; Industrialization; Knowledge and Skills; Metal Fabricating Firms; Small and Medium Enterprises

\section{Introduction}

Technological capability has received considerable attention of many researchers worldwide. This is with a view to understanding those factors responsible for the differences among the countries classified as developed, newly developed and less developed. In fact, technological capability is a major contributory factor to the paradigm shift that occurred in the ways nations relate and compete. Specifically, technological competitiveness, which researchers refer to as a game of nations, has been an indicator for measuring economic performance and standards of living of nations [1]. As a consequence, developed and developing nations are now categorized as having desirable and undesirable economic status respectively [2]. Hence, an attempt to move from the undesirable status, by the less developed nations, to the desirable status requires a technological ladder, which is explained to be synonymous to technological capability [2].

The realities in Africa however shows that many African countries are still struggling to get back on the developmental track after the aftermath of the Structural Adjustment Programme (SAP) introduced to the African economies by the World Bank [3]. Similarly, Nigeria is categorized as a developing nation with decreasing industrial productivity. Various research studies, together with expert opinions have attributed the failure to social, economic, and political factors. However, in addressing these challenges various policies have been adopted. One of such policy is International Technology Transfer (ITT) which is regarded as a factor to the success of the newly industrialized countries (NICs) of the East and SouthEast Asia [2]. This could be one of the reasons why most African governments depend on the industrialized and the newly industrialized nations for technological support to develop their economies.

But recently, there have been some shocking revelations from results of various researches in comparing various developmental activities among the newly Industrialized countries in Asia and some countries in Africa. The result shows that the pattern and the level of technological capability development among the two economic blocks are significantly different $[4,5]$.

Alternatively, researchers have therefore suggested rapid industrialization for developing economies to enhance economic development, and this in general term means raising the level of technological capability involved in the manufacturing activities [2,6] at all levels. Further studies have shown that every society has its own level of indigenous technical knowledge, and there are substantive literatures that established this knowledge to be very low in Africa [7] despite the endowment of many natural resources. It is based on this assertion that this 
study appreciates the significant role the metalworking sub-sector of the Nigerian manufacturing sectors has played in the industrialization effort of Nigeria, and at the same time, tries to understand the level of technological capability of operators in the sub-sector.

Amdi [8] notes that during the third and fourth national development plans of Nigeria, the metalworking sub-sector of the Nigerian manufacturing sector was identified as crucial for achieving rapid industrial development and technical change. This is because the sector is considered a centre-piece of any nation's real industrialization efforts. In fact, one of the factors that accelerate the industrial revolution in the industrialized nations of the world is attributed to the vibrant metalworking Industry [9]. This sector manufacture parts and components for automobile industry, construction industry, agricultural tools and equipment with wide applications and a number of basic household and industrial equipment [10]. Therefore, a technology-based metalworking industry is the bedrock of an industrialized nation. Furthermore, available literature revealed that there are various empirical works on technological and innovation capabilities in many areas of the Nigerian industrial sector, most especially in the manufacturing sector [11-13]. However, little of such studies have been directed towards the activities of the metal fabricators in Nigeria. Hence, the objective of this paper is to assess the activities of the metal fabricating firms as well as the capability of operators in the sector.

\section{Literature Review}

\subsection{Concept of Technological Capability}

Technological capability has been explained in various ways depending on the interest of the researchers. Garcia-Muina [14] conceptualized technological capability as a tool for implementing competitive strategy and creating value in any given environment. They further defined it as the ability to jointly mobilize different scientific and technical resources which enables a firm to successfully develop its innovative products or productive prcesses. Similarly, Marjolein [15] described technological capability as the ability to make the right investment choices; increase production capacity; and engage in continuous upgrading of product quality. They further argued that technological capability are efforts geared towards investment in time and resources aimed at assimilating, adapting and improving existing technologies and creating new technologies through reverse engineering.

Similarly, Jin [4] observed that technological capability in developing countries could be used interchangeably with "absorptive capacity" which means absorbing existing knowledge from the developed economy, assimilating it, and in turn generating new knowledge. The re- searchers further defined technological capability as the effective use of technical knowledge and skills required to improve and develop products and processes; improve existing technology; and also to generate new knowledge and skills in response to the competitive business environment.

The focus of technological capability in developing countries is on the relationship between the Firm-level Technological Capability (FTC) and the National-level Technological Capability (NTC). This focus at the firm level is on equipment, skills, knowledge, attitudes and aptitudes needed to choose, install, operate, maintain, understand, adapt, improve and develop technologies [5]. The process involves specific efforts and strategies by firms for developing technologies. At the national level, the focus is on collection of individual firm-level technological capabilities together with various linkages available in the National Innovation System (NIS) $[4,16,17]$.

In addition, technological capability can also be classified in terms of basic and key skills required by firms operating in a given country. These are the skills and knowledge required by firms to start a new business or upgrade an existing one. This type of technological capability is needed by firm to choose, install and operate a set of modern machinery and equipment that are widely used in a given industry. Basic technological capability is readily available to all competitors and it is the minimum requirement for standard production [9]. Key technological capability is required for the management of the effect of a technological change in a particular industry or system. It can be defined as the skills and knowledge required to operate, maintain, adapt and to improve on existing technologies. It gives the firm a competitive edge over other competitors and also allows the firm to compete favorably at the international market [9]. Furthermore, key technological capability can also create a technological change in an industry, where it discontinues an existing system and creates a new one.

Technological capability is composed of two broad elements, namely embodied and disembodied. The embodied elements of technological capability are those that involve the human aspect. It includes the skills, knowledge, attitude and aptitude. It is generally believed that these types of elements are tacit in nature and very difficult to measure or transfer [16]. The second is the nonembodied/disembodied elements. These are the part of technological capabilities that are codified and can easily be transferred among users. These include equipment and software [16].

\subsection{Indicators for Measuring Technological Capability}

At the firm-level, there are many indicators for measure- 
ing technological capabilities. These are based on the level of complexity and functionality of the four main categories of technological capabilities which include investment, production, innovation and linkage capabilities [5,7].

\subsubsection{Investment Capability}

Investment capability is described as the skills and information needed to identify feasible investment projects; prepare, locate and purchase technologies; staff, design and manage construction; commissioning and start-up. Under investment capability, the pre-feasibility and detailed feasibility study are prepared for the identified projects to determine the capital cost, sponsors, the appropriateness of the scale, product mix, technology and equipment to be used. The ability to undertake this process in-house has been considered to be important for firms [9].

Also, the economic viability and technical feasibility of the new project must be critically analyzed to determine the best combination of options for the project. This capability has been found to be very low among the African enterprises when compared with their counterpart from the industrialized and newly industrialized nations [7]. Alternatively, this function can be contracted out to be conducted by more experienced domestic or foreign firms that can help to perform the function effectively and efficiently. However, the method of external contract as observed, sometimes comes with its own associated challenges such as increase in the project's capital costs and the "not invented here" syndrome which make it difficult for the recipient to master, adapt and subsequently upgrade the technology [9].

\subsubsection{Production Capability}

Production capability is referred to as the skills and knowledge required for the operation of the production facilities. That is, once the two stages under the investment capability (Pre-investment and Project execution) have been completed, the production facilities need to be operated for optimum production. In achieving this, three different stages of activities with different levels of complexity were proposed in the literature. These are process engineering, product engineering and industrial engineering $[5,7]$. These three different activities combined together foster efficient and effective operation, maintenance, adaptation, improvement, quality and inventory control, work flow and scheduling, monitoring and so on for the newly commissioned production facilities $[5,7,18]$. In addition, Biggs [7] note that industrial engineering skills requires a good knowledge of mathematical, statistical and organizational techniques; time and motion studies; and layout and materials-handling analysis which will help to achieve productivity improvement through the change of time and sequence of manufacturing and auxiliary operations [7].

\subsubsection{Technology Innovation}

Innovation is the creation of value. It is an economic phenomenon involving the commercial use of new idea. Khalil [1] argued that innovation represents the important connection between an idea and its exploitation or commercialization. In the actual sense, innovation occurs after the first commercial transaction resulting from the introduction of the new product, process, or system. However, the length of time that usually separates the discovery of an invention, its application and exploitation which before now could take several years, have also reduced drastically. Also, innovation is a complex phenomenon [19] and like entrepreneurship, it appears in many fields of study [18]. Notwithstanding the largely shared views on the importance of innovation, several definitions for innovation types have been developed, resulting in an ambiguity in the term innovation [20]. To this end, this study define innovation as the scientific, technical, commercial and financial steps necessary for the successful development and marketing of new or improved processes, products or equipment; or the introduction of new approach to manufacturing activity [11].

\subsubsection{Innovation Capability}

Innovation capability is knowledge and skills needed to find new ways of carrying out the firm's activities such as investment, production, marketing and organizational as well as their implementation. Egbetokun [18] described innovation capability as 'search' capabilities and the capacity to actualize the outcome of the searching process. He further observed that the search for new routines is likely to create new patterns of human resource development, R \& D, technological information, technological adaptations and market research. Romijn [17] citing Lall [5] also defined innovation capability as the skills and knowledge needed to effectively absorb, master and improve existing technologies and to create new ones. Innovation capability has always been used for various organizational activities which cover ability to invent, innovate and improve existing technology beyond the original design parameters [21]. Therefore, for the purpose of this study, innovation capability will be referred to as the ability to make minor improvement and modifications to existing technologies and to create new technologies.

\subsubsection{Linkage Capability}

Linkage capability is a system used for transmitting and receiving supportive information at three different levels. These are within an enterprise; with other enterprises 
(intra-industry and inter-industry); and with R \& D institutions (local and overseas), including Universities [22]. Lall [23] conceived this capability as those skills that are required for transmitting information, skills and technology to, and receive them from component/raw material suppliers, customers, subcontractors, consultants, service firms and technology institutions. Linkage capability forms the basis for interaction among the above mentioned agents. It also boost access to information about markets, technologies, technical assistance, research and technical knowledge [24] as well as learning facilities, on which the process of building technological capability lies. Other observed forms of linkages as highlighted by Egbetokun [18] include licensing, management and marketing agreements; joint ventures; interaction with local and foreign competitors; government policy and regulations, interactions with domestic and international finance institutions and so on.

\section{Research Methodology}

To determine the technological capability of individual fabricating firm in the study area, random sampling techniques was employed in taking sample of 200 metal fabricating firms from the registers of the Manufacturers Association of Nigeria (metal fabrication sub-section) and the State Ministry of Commerce and Industry. The survey covers Lagos and Ogun States in Southwestern Nigeria. Lagos State was selected because of the high industrial activities which have contributed to the large population and clustering of many manufacturing firms in the area, while Ogun State was selected due to the influx of manufacturing firms to the area in search of a large factory space for their manufacturing operations. A set of questionnaire was used for collection of the primary data from the respondents. Draft of the questionnaire adapted from similar studies elsewhere was sent to six purposively selected individual stakeholders in the academics, government research institutes and the Industry as a pre-test. The data collected were subjected to reliability test (Cronbach's $\alpha$ : 0.839 to 0.855 ).

Technological capability index (TCI) which composed of four (4) variables was developed. These variables are investment, production, innovation and linkage capabilities. Each of these variables represents the taxonomies of technological capability developed by Lall [5] and has been widely adopted and used as a standard for operationalizing technological capability at micro-level [25]. The variables measured were grouped into investment; process, product and industrial engineering; process and product innovation; and linkage functional areas. The variables were further graded using a rating scale of 2 (systematic), 1 (ad-hoc), and 0 (None) which represents different level of competence. A firm is however awarded a score based on its level of competence in performing these technical functions as described under each of the variables. In all, a given metal fabricating firm was assessed out of a total capability score of fifty two (52), and the result was normalized between 0 and 2 to give the TCI.

\section{Results and Discussions}

\subsection{Investment Capability of Responding Firms}

Table 1 shows the investment capability of responding firms. Investment capabilities, as noted earlier, are the skills and information needed to identify feasible investment projects, locate and purchase suitable technologies, design and engineer the plant, and manage the construction, commission and start-up. The response confirms that majority of the firms in the survey were above average in the area of investment capability. The percentage of firms that indicated no compliance with investment functions were $2.3 \%, 31.6 \%$ and $39.1 \%$ for search and selection of technology; detailed engineering; and recruitment and training of technical personnel activities respectively. However, about half of those that indicated their compliance with pre-investment and project execution activities did so in an unplanned manner (Ad-hoc).

\subsection{Production Capability}

Production capability was considered under process, product and industrial engineering functions. These functions include debugging and calibration of new equipment, replacing original equipment parts, quality control,

Table 1. Investment capability of the responding firms.

\begin{tabular}{lccc}
\hline Investment functions & No & Ad-hoc & Systematic \\
\hline Feasibility studies for new factories, workshop or projects & - & $87(62.6)$ & $46(34.6)$ \\
Search for \& select technology for new projects & $3(2.3)$ & $69(51.9)$ & $61(45.9)$ \\
Detailed engineering for new projects & $42(31.6)$ & $45(33.8)$ & $46(34.6)$ \\
Construction of workshop facilities & - & $121(91.0)$ & $12(9.0)$ \\
Recruitment \& training of technical personnel & $52(39.1)$ & $43(32.3)$ & $38(28.6)$ \\
\hline
\end{tabular}

Note: Figures in parentheses are row percentages. 
reproduction of fixed specifications and designs, accreditation and certification of product quality, design and introduction of new products in-house, operation of inventory control system, scheduling production, and monitoring of productivity. Table 2 shows that firms displayed capability in production that was similar to that of investment capability except for accreditation/certification of product quality (56.4\%) that was above average for no compliance. Also, other activities were mostly conducted in a manner that is either systematic or ad-hoc.

\subsection{Innovation Capability}

Innovation capability consists of the potential of a firm to search for ways of carrying out its key activities and the capacity to internalize the outcome of such searches. Table 3 shows that $97.0 \%$ and $75.2 \%$ firms did not understand the function of process innovation as a strategy for developing new production method and modification to existing production process respectively. Other activities followed the observed pattern of well above average compliance in capability.

\subsection{Linkage Capability}

Interactions with various actors in the National Innovation System constitute one of the most important learning and innovation efforts for African firms [18,23,26]. However, Table 4 shows a weak linkage capability between the firms and actors in the National Innovation System except for collaboration with the trade association where $91.0 \%$ of the firms demonstrated high level of formal cooperation. This suggests that firms in the fabriccating industry, whether in the formal or informal sector, belong to one form of trade association. Similarly, networking with other fabricating firms are $60.2 \%$ ad-hoc and $9.0 \%$ systematic; while collaboration with customers/suppliers are $66.2 \%$ ad-hoc and $12.0 \%$ systematic. Firms in the study area have poor linkage activity with educational and research institutes (91.7\%) and financial institution (72.9\%).

\subsection{Innovations in the Metal Fabricating Firms}

Table 5 shows the sampled firms degree of novelty. The

Table 2. Production capability of the responding firms.

\begin{tabular}{lccc}
\hline Production functions & No & Ad-hoc & Systematic \\
\hline Debugging \& calibration of new equipment & $59(44.4)$ & $27(20.3)$ & $47(35.3)$ \\
Do routine maintenance operation & $65(48.9)$ & $40(30.1)$ & $28(21.1)$ \\
Replacing original equipment parts & $28(21.1)$ & $77(57.9)$ & $28(21.1)$ \\
Quality control (Automated/Vision) & - & $100(75.2)$ & $33(24.8)$ \\
Reproduce fixed specifications and designs & - & $48(36.1)$ & $85(63.9)$ \\
Accreditation/certification of product quality & $75(56.4)$ & $42(31.6)$ & $16(12.0)$ \\
Design \& introducing new products in-house & $42(31.6)$ & $53(39.8)$ & $38(28.6)$ \\
Operating inventory control system & $18(13.5)$ & $78(58.6)$ & $37(27.8)$ \\
Scheduling production & - & $72(54.1)$ & $61(45.9)$ \\
Monitoring of productivity & - & $100(75.2)$ & $33(24.8)$ \\
\hline
\end{tabular}

Note: Figures in parentheses are row percentages.

Table 3. Innovation capability of the responding firms.

\begin{tabular}{lccc}
\hline Innovation functions & No & Ad-hoc & Systematic \\
\hline Develop new production method & $129(97.0)$ & $4(3.0)$ & - \\
Introduce new production method & - & $50(37.6)$ & $83(62.4)$ \\
Modification to existing production method & $100(75.2)$ & $33(24.8)$ & - \\
Develop new product(s) & $30(22.6)$ & $67(50.4)$ & $36(27.1)$ \\
Copy/imitation of imported product(s) & $6(4.5)$ & $40(30.1)$ & $87(65.4)$ \\
Modification to existing product(s) & $19(14.3)$ & $34(25.6)$ & $80(60.2)$ \\
\hline
\end{tabular}

Note: Figures in parentheses are row percentages. 
Table 4. Linkage capability of the responding firms.

\begin{tabular}{lccc}
\hline Linkage functions & No & Ad-hoc & Systematic \\
\hline Networking with other firms & $41(30.8)$ & $80(60.2)$ & $12(9.0)$ \\
Association with trade union & $12(9.0)$ & - & $121(91.0)$ \\
Collaboration with educational and research institutes & $122(91.7)$ & - & $12(8.3)$ \\
Relationship with customers/suppliers & $29(21.8)$ & $88(66.2)$ & $16(12.0)$ \\
Relationship with financial institution & $97(72.9)$ & - & $36(27.1)$ \\
\hline
\end{tabular}

Note: Figures in parentheses are row percentages.

Table 5. Innovation in the metal fabricating firms.

\begin{tabular}{lcc}
\hline Degree of novelty & Product & Process \\
\hline Radical innovation & - & $36(27.1)$ \\
Incremental innovation & $33(24.8)$ & $114(85.8)$ \\
New to the firm/ imitation & $133(100.0)$ & $127(95.5)$ \\
Creativity & $4(3.0)$ & $67(50.4)$ \\
\hline
\end{tabular}

Note: Figures in parentheses are sample percentages.

objects of innovation observed are classified into radical, incremental, new to the firm/imitation and creativity. Process innovation is very weak throughout the industry. There were however 33(24.8\%) and 4(3.0\%) cases of incremental innovation and creativity respectively. Also, $133(100 \%)$ firms confirmed the introduction of new production method (new to the firm) into their business as part of their innovative effort. By contrast, product innovation is highly prevalent throughout the sector with the incidence of radical (27.1\%), incremental (85.8\%), imitation/copying (95.5\%) and creativity (50.4\%) activeties in the industry. Only, 'new to the firm' type of process innovation agree with the findings of Egbetokun [8] in their study of innovation capability in the cable and wire manufacturing industry in Nigeria, where the incidence of process innovation (0.8) was higher than product innovation (0.6).

\subsection{Technological Capability Index}

Table 6 shows the frequency distribution of the technological capability index (TCI) scores for the 133 metal fabricating firms. The data shows a variation in the TCI scores of fabricating firms in relation to the size of firms. Almost all the medium-size firms had scores of between 1.41 and 1.80 except one (1) firm which has a score below 1.41. The TCI scores for majority of the micro firms were between 0.61 to 1.00 while most small firms had TCI scores of between $1.01-1.40$. From this result, while the medium firms (1.41 - 1.60 and $1.61-1.80)$ had technological capabilities that compared well with those found in the developed countries; however, the overall
Table 6. Technological capability index by firm size.

\begin{tabular}{cccc}
\hline \multirow{2}{*}{ TCI class } & \multicolumn{3}{c}{ Firm size } \\
\cline { 2 - 4 } & Micro & Small & Medium \\
\hline $0.00-0.20$ & - & - & - \\
$0.21-0.40$ & - & - & - \\
$0.41-0.60$ & - & - & - \\
$0.61-0.80$ & 29 & 1 & - \\
$0.81-1.00$ & 24 & 17 & - \\
$1.01-1.20$ & 6 & 22 & - \\
$1.21-1.40$ & - & 16 & 1 \\
$1.41-1.60$ & - & - & 12 \\
$1.61-1.80$ & - & - & 5 \\
$1.81-2.00$ & - & - & - \\
Total & 59 & 56 & 18 \\
\hline
\end{tabular}

technological capability of the firms sampled is far below the average obtainable in the fabricating industry internationally.

\section{Average Technological Capability Index}

Table 7 shows the average TCI scores for all firms according to their size; and the corresponding average scores for individual capabilities (INVT I., PDTN I., INNO I., and LNKG I.) that make-up the TCI scores. The average TCI clearly shows a better result according to the firm size. It reveals the difference in the level of technological capability among the various firm sizes (micro, small, and medium) of metal fabricating firms in Southwestern Nigeria. The micro firms have an average TCI score of 0.82 , which is considered to be very low, and even below the total average TCI scores (1.00). The average TCI score (1.10) of the small firms is a little above the average TCI score. The medium scale firms have an average TCI score of 1.54 which is considered to be the highest. Further analysis based on the individual capabilities that make up the TCI revealed the differences 
Table 7. Distribution of average TCI.

\begin{tabular}{ccccccc}
\hline \multirow{2}{*}{ Firm size } & \multirow{N}{*}{$\mathrm{N}$} & \multicolumn{5}{c}{ Score } \\
\cline { 3 - 7 } & & TCI & INVT. I & PDTN. I & INNO. I & LNKG. I \\
\hline Micro & 59 & 0.82 & 0.93 & 0.84 & 0.82 & 0.68 \\
Small & 56 & 1.10 & 1.17 & 1.15 & 1.13 & 0.89 \\
Medium & 18 & 1.54 & 1.89 & 1.73 & 1.20 & 1.22 \\
\hline
\end{tabular}

Note: $\mathrm{N}$ indicates number of firms; TCI-Technological Capability Index; INVT. I-Investment Index; PDTN. I-Production Index; INNO. I-Innovation index; LNKG. I—Linkage Index.

and the nature of technological activities of all the sectors (micro, small, and medium) of sampled firms. The investment index reveals that the micro, small, and medium firms had scores of $0.93,1.17$ and 1.89 respectively. Comparably, the data suggests a big technological gap in the investment capability when a comparison is made between micro, small and medium firms. Also, production and linkage capabilities followed a similar pattern as observed in the investment capability. The production index scores were micro (0.84), small (1.15) and medium (1.73) firms for production capability while the linkage index scores are $0.68,0.89$ and 1.22 for micro, small and medium firms respectively for linkage capability.

Furthermore, by comparing the difference among these capabilities that followed the same pattern, production capability presented a difference value of 0.58 . This could be as the result of some quality control tests like Pressure test, Radiography (X-ray), fatigue and hydro test conducted by medium firms on their various metal products. Whereas, the micro and small enterprises mostly based their quality control on much of raw materials selection, vision and hydro test of their finished products. They did not perceive any advantage that product quality certification provides to their business, as none of the products of the firms was certified. In a similar manner, linkage capability showed a difference of 0.33 between the medium and small firms. This suggests that medium firms have better networking arrangement with other MSMEs fabricating firms. The medium firms on many occasions engage the services of the other firms by outsourcing part of their on-going projects to these firms. This type of relationship has numerous advantages of transferring the best practice from the medium firms to the micro firms in the sector. However, networking with other fabricating firms between small and micro firms seems to be absent or weak where available. Lastly, investment capability revealed a capability difference of 0.72 between the medium and small fabricating firms. This difference reflects in the way medium firms conduct their recruitment and training exercise for new technical staff. Also, innovation capability shows a similar pattern. The innovation index scores are 0.82, 1.13 and 1.20 for the micro, small and medium firms respectively, with medium firms coming out stronger than other category of sampled firms. In addition, innovation index scores seem to explain the difference in the average TCI scores between medium and small firms. This suggests that small and medium firms are good imitators. They seem to adopt technology follower strategy [27] as a catch-up for developing their technological capability.

\section{Conclusion and Recommendations}

Majority of the micro and small fabricating firms in southwestern Nigeria had low technological capability. This was found to be lower than that obtainable in the industry. However, the medium fabricating firms operating in the same area have a technological capability which is at par with international best practice in the metal fabricating industry. Metal fabricating firms in southwestern Nigeria seems to have considerable capability in investment and production, while their performance in innovation and linkage capabilities are weak. The major innovations found among the metal fabricating firms in Southwestern Nigeria are products and introduction of new production method, while process innovations is still lacking. In addition, the main sources of innovations for the fabricating firms are imitations and copying from imported products.

The study concludes that there is need for policy intervention to enhance the knowledge and skills of these operators with a view to improving the technological capability and productivity of the metal fabricating firms. This will enhance their national competitiveness and comparative advantage in the globalized economy.

\section{REFERENCES}

[1] T. Khalil, "Competitiveness," In: T. Khalil, Ed., Management of Technology: The Key to Competitiveness and Wealth Creation, Thomas Casson, 2000, pp. 153- 191.

[2] F. Ogbimi, "Solution to Mass Unemployment in Nigeria," In: F. Ogbimi, Ed., Achieving Rapid Industrialisation and Democratisation in Nigeria, Obafemi Awolowo University Press, Ile-Ife, 2007.

[3] A. Hoogvelt, "Industry and Trade in a Global Economy with Special Reference to Sub-Saharan Africa,” Industrial Policies and Research, United Nations Industrial Development Organization, 2000.

http://www.unido.org/fileadmin/user_media/Publications/ Pub_free/Industry_and_trade_in_a_global_economy_with_ special_reference_to_subSaharan_Africa.pdf

[4] J. Jin, and M. Von Zedtwitz, "Technological Capability Development in China's Mobile Phone Industry," Technovation, Vol. 28, No. 6, 2008, pp. 327-334.

doi:10.1016/j.technovation.2007.06.003

[5] S. Lall, "Technological Capabilities and Industrialisation," World Development, Vol. 20, No. 2, 1992, pp. 165-186. doi:10.1016/0305-750X(92)90097-F 
[6] E. Dike, "Vision 2020: Where is the Technological Capability?” 2009.

http://www.nigeriavillagesquare.com/articles/guest-article s/vision-2020-where-is-the-technological-capability.html

[7] T. Biggs, M. Shah and P. Srivastava, "Technological Capabilities and Learning in Africa Enterprises,” World Bank Technical Paper, Washington DC, 1999.

[8] I. E. S. Amdi, "Institutions Supporting Technical Change in Nigeria: The Role of Industrial Development Centres," 1995.

http://web.idrc.ca/en/ev-30805-201-1-DO_TOPIC.html

[9] D. Pierre, H. Staut and R. Bernard, "Strategic Technology Management: Integrating Product Technology into Global Business Strategies for the 1990s,” John Wiley and Sons, Hoboken, 1992.

[10] G. Laditan, "Upgrading Technologies in the Small Scale Metal Working Industry in Nigeria: A Case Study of Oyo and Osun States," Nigeria Institute of Social and Economic Research Monograph, Ibadan, 1997.

[11] I. Abereijo, "Evaluation of Capabilities of Small and Medium Industrial Enterprises for Acquisition of $\mathrm{New}$ Technologies in Southwest Nigeria,” M.Sc. Thesis, Obafemi Awolowo University, Ile-Ife, 2006.

[12] A. Egbetokun, W. Siyanbola and A. Adeniyi, “Assess- ment of Innovation Capability in the Cable and Wire Manufacturing Industry in Nigeria: A Case Study Approach,” 2007. http://www.merit.unu.edu/MEIDE/papers/2007/EGBETO KUN_SIYANBOLA_ADENIYI_Assessment\%20of\%20i nntion\%20capability...cable\%20\&\%20wire\%20manufact uring\%20industry.pdf

[13] S. Oke, “An Evaluation of the National Innovation System and Technological Capability Building in the Manufacturing Sector," M.Sc. Thesis, Obafemi Awolowo University, Ile-Ife, 2005.

[14] F. Garcia-Muina and J. Navas-Lopez, "Explaining and Measuring Success in New Business: The Effect of Technological Capabilities on Firm Results,” Technovation, Vol. 27, No. 1-2, 2007, pp. 30-46. doi:10.1016/j.technovation.2006.04.004

[15] C. Marjolein and H. Romijn, "Technological Learning in Small Enterprise Clusters: Conceptual Framework and Policy Implications,” In: S. Mani and H. Romijn, Eds., Innovation, Learning and Technological Dynamism of Developing Countries, UNU Press, Tokyo and New York, 2004, pp. 135-157.

[16] M. Gillian, “Technological Learning: A Strategic Imperative for Firms in Developing World," Edward Elgar Publishing Limited, UK, 2004.
[17] H. Romijn and M. Albaladejo, "Determinants of Innovation Capability in Small Electronics and Software Firms in Southeast England," Research Policy, Vol. 31, No, 7, 2002, pp. 1053-1067. doi:10.1016/S0048-7333(01)00176-7

[18] A. Egbetokun, “Assessment of Innovation Capability in the Cable and Wire Manufacturing Industry in Nigeria: A Case Study Approach,” M.Sc. Thesis, Obafemi Awolowo University, Ile-Ife, 2009.

[19] H. Armbruster, A. Bikfalvi, S. Kinkel and G. Lay, “Organisational Innovation: The Challenge of Measuring Nontechnical Innovation in Large Scale Surveys,” Technovation, Vol. 28, No. 7, 2008, pp. 644-657. doi:10.1016/j.technovation.2008.03.003

[20] R. Garcia and R. Calantone, "A Critical Look at Technological Innovation Typology and Innovativeness Terminology: A Literature Review," Journal of Product Innovation Management, Vol. 19, No. 2, 2002, pp. 110-132. doi:10.1016/S0737-6782(01)00132-1

[21] L. Kim, "Imitation to Innovation: The Dynamics of Korea’s Technological Learning,” Harvard Business School Press, Boston, 1997.

[22] O. Olamade, "Technological Capabilities in the Nigerian Telecommunication Industry,” M.Sc. Thesis, Obafemi Awolowo University, Ile-Ife, 2001.

[23] S. Massa and S. Testa, "Innovation and SMES: Misaligned Perspectives and Goals among Entrepreneurs, Academics and Policy Makers,” Technovation, Vol. 28, No. 7, 2008, pp. 393-407. doi:10.1016/j.technovation.2008.01.002

[24] N. Amara, R. Landry, N. Becheikh and M. Ouiment, "Learning and Novelty of Innovation in Established Manufacturing SMEs,” Technovation, Vol. 28, No. 7, 2008, pp. 450463. doi:10.1016/j.technovation.2008.02.001

[25] G. Wignaraja, "Firm Size, Technological Capabilities and Market-Oriented Policies in Mauritius,” Discussion Papers Series of the United Nations University, Institute for New Technologies, 2001.

[26] M. Ilori, "From Science to Technology and Innovation Management,” Obafemi Awolowo University Press Limited, Ile-Ife, 2006.

[27] S. Sanni and M. Ilori, "Strategic Management of Technology: Readings in Technology Management,” National Centre for Technology Management Monograph, Ile-Ife, 1999, pp. 43-56. 